\title{
Introduction of complete mesocolic excision with central vascular ligation as standardized surgical treatment for colon cancer in Greece. Results of a pilot study and bi-institutional cooperation
}

\author{
Aristotelis Perrakis ${ }^{1,2}$, Nikolaos Vassos ${ }^{1}$, Klaus Weber ${ }^{1}$, Klaus E. Matzel ${ }^{1}$, \\ Konstantinos Papadopoulos ${ }^{3}$, Georgios Koukis ${ }^{3}$, Evangelos Perrakis ${ }^{3}$, Roland S. Croner ${ }^{1,2}$, \\ Werner Hohenberger ${ }^{1}$
}

${ }^{1}$ Department of Surgery, University Hospital Erlangen, Erlangen, Germany
2Department of Surgery, University Hospital Magdeburg, Magdeburg, Germany
${ }^{3} 1^{\text {st }}$ Surgical Department, General Hospital of Piraeus/Nikaia, Piraeus/Nikaia, Greece

Submitted: 10 July 2018

Accepted: 28 September 2018

Arch Med Sci 2019; 15 (5): 1269-1277

DOI: https://doi.org/10.5114/aoms.2018.80040

Copyright (c) 2018 Termedia \& Banach

\section{Abstract}

Introduction: Complete mesocolic excision (CME) is generally accepted as state of the art in colon cancer surgery. However, the long-term impact of CME has not been systematically examined. Therefore cohort studies might be a possible way to clarify any differences between conventional resections and CME. Following bilateral cooperation between the Department of Surgery/University Hospital of Erlangen and the $1^{\text {st }}$ Surgical Department of the General Hospital of Nikaia/Piraeus, including teaching activities for introduction of CME, a cohort study was performed, considering surgical quality criteria and clinical outcome.

Material and methods: All patients with colon carcinomas (CME group, $n=31$ ) referred to the $1^{\text {st }}$ Surgical Department of General Hospital, Nikaia/ Piraeus, Greece for surgery from January 2012 to December 2013 were prospectively analyzed and compared with patients who underwent conventional surgery for colon cancer between January 2008 and December 2011 (non-CME group, $n=35$ ). Patients' follow-up was at least 48 months.

Results: There were significantly better results in terms of lymph node yield (CME group: 29.6 vs. non-CME group: 17.85; $p<0.001$ ) and lymph node ratio (LNR) (CME group: 0.12 vs. non-CME group: $0.24 ; p<0.001)$ and recurrence-free survival in favor of the CME group (CME group: $n=0$ vs. non-CME group: $n=5$ ) without any increase in surgical morbidity (CME group: $n=6$ vs. non-CME group: $n=11 ; p=0.10$ ).

Conclusions: Complete mesocolic excision appears to offer a superior oncological result without any increase of postoperative morbidity and mortality. Furthermore, CME represents a surgical technique which can be established in a surgical department after previous teaching without increasing the postoperative complication rate.

Key words: colon carcinoma, complete mesocolic excision, central vascular ligation, lymph node, surgery.

\section{Introduction}

Complete mesocolic excision (CME) with central vascular ligation (CVL) is performed according to the same oncological principles as total me-
Corresponding author: Nikolaos Vassos MD Department of Surgery University Hospital Erlangen Krankenhausstr. 12 D-91054 Erlangen Germany Phone: +49 91318533296 Fax: +49 91318539227 E-mail: nikolaos.vassos@ uk-erlangen.de 
sorectal excision (TME) surgical technique [1-9]. However, performing CME for right-sided colon carcinomas and especially in cases of carcinomas of the transverse colon is a more complex procedure $[1,10]$. Complete mesocolic excision procedure includes the excision of the entire mesocolon in the region of tumor in an intact package following embryologic tissue planes. After standardization of this procedure, excellent 5-year survival rates (5-year cancer-related survival: 89\%, local recurrence: $<4 \%$ after $\mathrm{RO}$ resection) have been achieved combined with low surgical morbidity and very low in-hospital mortality rates, although emergencies are included [1-4]. Especially in patients with stage III disease, 5-year cancer-related survival rates are higher than $70 \%$. Furthermore, a maximum of lymph node harvesting can be achieved by following the principles of CME [10-16]. However, the technique remains controversial and the evidence of increased disease-free survival after CME in comparison to conventional surgery of colon carcinoma remains an open question.

Nevertheless, systematic data concerning the impact of CME with CVL concerning the long term and comparative results do not exist [17-19]. Therefore cohort studies comparing CME with conventional colon cancer resections might be the only way to clarify any differences between CME and conventional resections. After the successful introduction of CME in several countries with positive results regarding the quality of surgery [20, 21], our intention was to extend our collaboration network in Greece and to standardize the treatment of colon cancer in Greece in terms of CME. Therefore bilateral cooperation including teaching activities between the Department of Surgery/ University Hospital of Erlangen and the $1^{\text {st }}$ Surgical Department of the General Hospital of Nikaia/ Piraeus has been established. Our aim was the systematic introduction of oncologic surgery for colon cancer in terms of CME with CVL in Greece

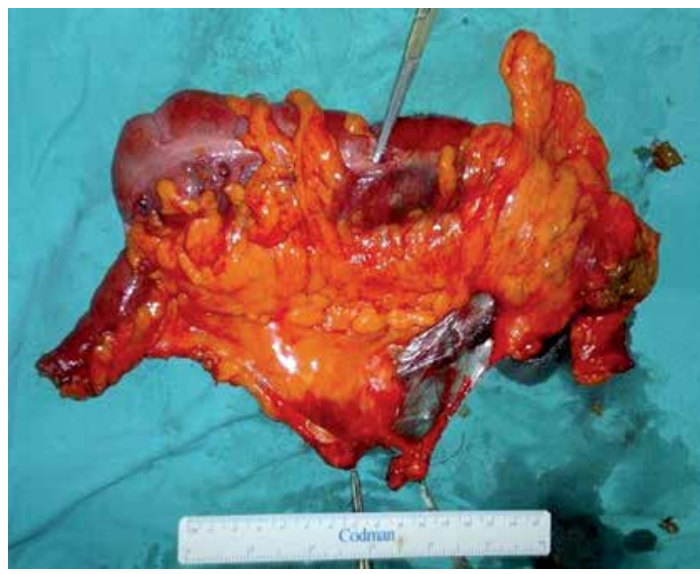

Figure 1. Specimen after right hemicolectomy (the upper clamp shows the site of the tumor; the 2 clamps at the bottom show the marking of the $\mathrm{CVL}$ ) and assessment of the impact of this surgical technique in terms of oncological outcome.

\section{Material and methods}

After obtaining permission from the local authorities of Greece and Germany for exchange of personnel between the two institutions and after the approval of the ethics committee of both hospitals, we identified and prospectively analyzed all patients with colon carcinomas $(n=31)$ referred to and treated at the $1^{\text {st }}$ Surgical Department of General Hospital, Nikaia/Piraeus from January 2012 to December 2013. Patients of this group underwent surgery by a selected group of surgeons (E.P., K.P., G.K., A.P.) who gained training and experience in CME by either visiting the Department of Surgery/University Hospital of Erlangen or by selected personnel (A.P., N.V.) This patients' collective was compared with another collective - including 35 patients (nonCME group) who underwent conventional colon carcinoma surgery from January 2008 to December 2011 without undergoing CME with CVL - in order to evaluate qualitative markers (number of excised lymph nodes, lymph node ratio) and long-term outcomes (cancer-/recurrence-free survival) and to compare the morbidity and mortality rates.

Clinical (age, gender, ASA classification, site of tumor, surgical procedure, type of surgery) and histopathological (tumor grade and stage) parameters as well as short- and long-term outcomes (morbidity, mortality, cancer-free and recurrence-free survival) were prospectively collected from a standardized database and included in our analysis. In the current analysis we did not include patients with inflammatory bowel disease and familial adenomatous polyposis. All specimens were photo documented and evaluated for surgical quality - in terms of mesocolic plane, lymph node harvesting and lymph node ratio (LNR) (Figures 1, 2). Clinical and histopathological characteristics are presented in Table I.

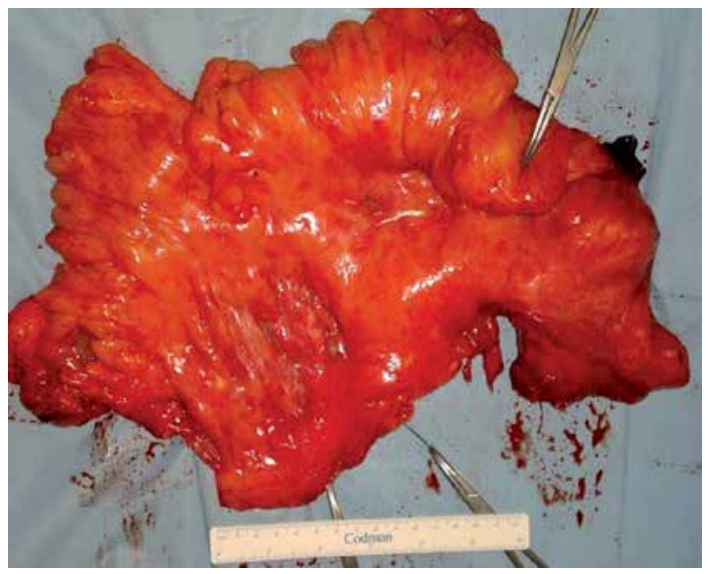

Figure 2. Specimen after sigmoid resection for cancer (the upper clamp shows the site of the tumor and the 2 clamps on the other side the supplying vessels) 
Introduction of complete mesocolic excision with central vascular ligation as standardized surgical treatment for colon cancer in Greece. Results of a pilot study and bi-institutional cooperation

Table I. Clinical and histopathological characteristics in CME $(n=31)$ and non-CME $(n=35)$ group

\begin{tabular}{|c|c|c|c|}
\hline Parameter & $\begin{array}{c}\text { CME group } \\
(n=31) \\
n(\%) \text { or mean (range) }\end{array}$ & $\begin{array}{c}\text { Non-CME group } \\
(n=35) \\
n(\%) \text { or mean (range) }\end{array}$ & $P$-value \\
\hline Age [years] & $75(55-84)$ & $69(29-89)$ & 0.024 \\
\hline \multicolumn{4}{|l|}{ Gender: } \\
\hline Male & $14(45)$ & $17(49)$ & 0.167 \\
\hline Female & $17(55)$ & $18(51)$ & 0.158 \\
\hline \multicolumn{4}{|l|}{ ASA classification: } \\
\hline ASA I & $0(0)$ & $6(17)$ & $<0.001$ \\
\hline ASA II & $14(45)$ & $11(32)$ & 0.018 \\
\hline ASA III & $17(58)$ & $18(51)$ & 0.658 \\
\hline \multicolumn{4}{|l|}{ Site of tumor: } \\
\hline Caecum & $6(19)$ & $9(26)$ & 0.081 \\
\hline Ascending colon & $10(32)$ & $6(17)$ & 0.034 \\
\hline Transverse colon & $2(7)$ & $5(13)$ & 0.146 \\
\hline Hepatic flexure & $2(7)$ & $3(9)$ & 0.473 \\
\hline Splenic flexure & $0(0)$ & $1(3)$ & $<0.001$ \\
\hline Descending colon & $0(0)$ & $1(3)$ & $<0.001$ \\
\hline Sigmoid colon & $11(35)$ & $10(29)$ & 0.537 \\
\hline \multicolumn{4}{|l|}{ Surgical procedure: } \\
\hline Right hemicolectomy & $16(52)$ & $15(42)$ & 0.586 \\
\hline Sigmoidectomy & $11(35)$ & $10(29)$ & 0.537 \\
\hline Subtotal colectomy & $2(7)$ & $2(6)$ & 0.894 \\
\hline Extended right hemicolectomy & $2(7)$ & $8(23)$ & 0.034 \\
\hline \multicolumn{4}{|l|}{ Type of surgery: } \\
\hline Elective & $24(77)$ & $27(77)$ & 0.769 \\
\hline Emergency & $7(23)$ & $8(23)$ & 0.128 \\
\hline \multicolumn{4}{|l|}{ Tumor stage: } \\
\hline pT2 & $9(29)$ & $5(14)$ & 0.027 \\
\hline pT3 & $18(58)$ & $27(77)$ & 0.015 \\
\hline pT4 & $4(13)$ & $3(9)$ & 0.489 \\
\hline pNO & $15(48)$ & $21(60)$ & 0.137 \\
\hline $\mathrm{pN}+:$ & $16(52)$ & $14(40)$ & 0.494 \\
\hline $\mathrm{pN} 1$ & $9(29)$ & $7(20)$ & 0.149 \\
\hline pN2 & $7(23)$ & $7(20)$ & 0.892 \\
\hline MO & $27(87)$ & $32(91)$ & 0.917 \\
\hline M1 & $4(13)$ & $3(9)$ & 0.649 \\
\hline Hepatic & 4 & $2(6)$ & 0.337 \\
\hline Peritoneal & & $1(3)$ & $<0.001$ \\
\hline
\end{tabular}


Table I. Cont.

\begin{tabular}{|lccc|}
\hline Parameter & $\begin{array}{c}\text { CME group } \\
(n=31) \\
n(\%)\end{array}$ & $\begin{array}{c}\text { Non-CME group } \\
(n=35)\end{array}$ & $P$-value \\
\hline Lymph node yield and ratio: & & 17.85 & $<0.001$ \\
\hline Lymph node yield & 29.6 & 0.18 & 0.01 \\
\hline LNR (UICC stage III) & 0.095 & 0.24 & $<0.001$ \\
\hline LNR (overall) & 0.12 & $5(14)$ & 0.027 \\
\hline UICC stage: & & $16(46)$ & $<0.001$ \\
\hline I & $9(29)$ & $11(31)$ & 0.559 \\
\hline II & $6(19)$ & $3(9)$ & 0.489 \\
\hline III & $12(39)$ & & NS \\
\hline IV & $4(13)$ & $0(0)$ & $<0.001$ \\
\hline Tumor grade: & $0(0)$ & $30(86)$ & $<0.001$ \\
\hline Well-differentiated (G1) & $21(68)$ & $5(14)$ & \\
\hline Moderately differentiated (G2) & $10(32)$ & & \\
\hline Poorly differentiated (G3) & & & \\
\hline
\end{tabular}

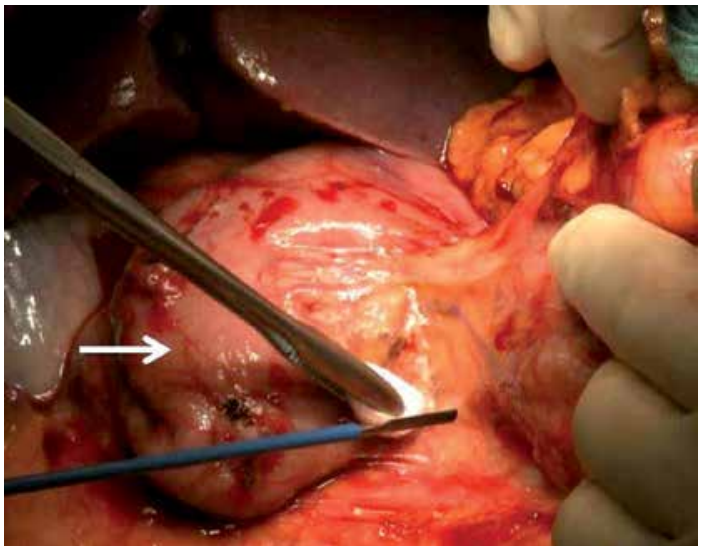

Figure 3. Dissection of mesocolon from mesopancreas over the head of the pancreas (white arrow shows the duodenum)

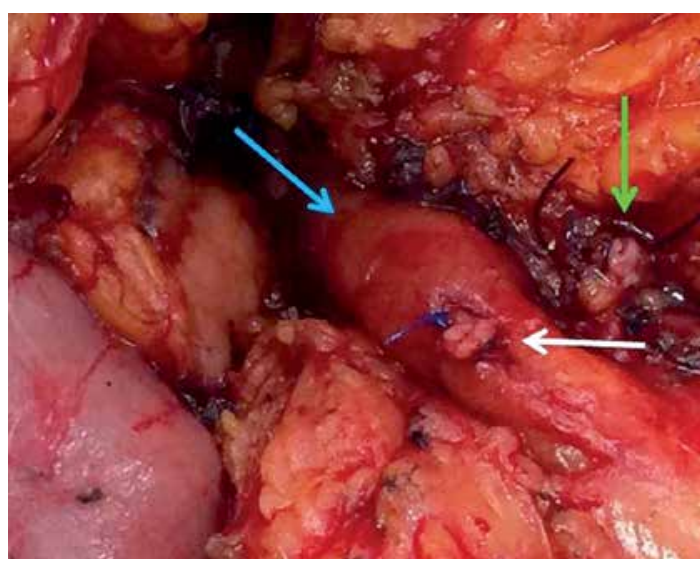

Figure 4. Central vascular ligation (CVL) (white arrow shows the CVL of the ileocolic artery, green arrow shows the central ligation of the ileocolic vein, blue arrow shows the superior mesenteric artery (AMS))

\section{Surgical technique and intraoperative/} postoperative data

In all cases (CME group), open colon resection was performed with CME (Figure 3), formal regional lymph node dissection and CVL (Figure 4) as described by Hohenberger et al. [1], with dissection of all relevant lymph node regions. In cases of flexure or transverse colon carcinoma, the resected lymph node regions included the infrapancreatic lymph nodes (ILR, Figure 5), the lymph nodes over the head of the pancreas and the lymph nodes around the gastroepiploic arcade (GLR) [10]. Patients with either lymph node metastasis or distant metastases were treated additionally with systemic chemotherapy. Patients with bowel obstruction or perforation under-

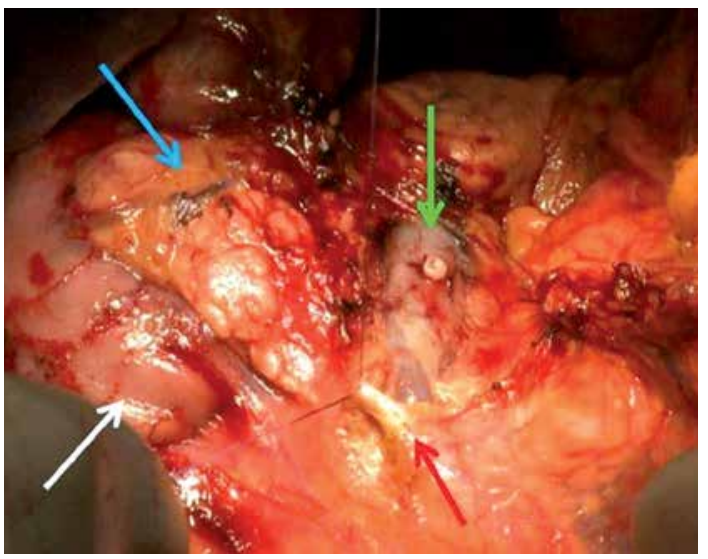

Figure 5. Infrapancreatic lymph node region and dissection (white arrow shows the duodenum, blue arrow shows the head of the pancreas, green shows the superior mesenteric vein (VMS), red arrow shows the $\mathrm{CVL}$ ) 
went emergency surgery, meaning surgery within $48 \mathrm{~h}$ after admission.

\section{Statistical analysis}

The statistical analysis was performed using statistical software (SPSS Statistics V21.0; IBM North America, New York, NY and Excel 2010; Microsoft, Redmond, WA) and all data were checked for significance using non-parametric statistical tests: the Wilcoxon signed-rank test for continuous data and the $\chi^{2}$-test for categorical data. A $p$-value $<0.05$ was considered statistically significant. Continuous variables are reported as the mean \pm deviation.

\section{Results}

\section{Follow-up}

Long-term follow-up of patients was achieved (median: 60 months; range: 36-108 months). Follow-up was performed in the interdisciplinary colorectal unit of the General Hospital, Nikaia/Piraeus, and patients were examined by a surgeon and a medical oncologist.

\section{CME group (2012-2013)}

\section{Site of carcinoma in CME group $(n=31)$}

The colon carcinoma was located in the caecum ( $n=6,19 \%)$, ascending colon $(n=10 ; 32 \%)$, hepatic flexure $(n=2 ; 6 \%)$, transverse colon $(n=2 ; 6 \%)$ and sigmoid colon ( $n=11 ; 35 \%)$. Twenty-four patients underwent elective surgery and 7 patients underwent the same surgical procedure as emergency cases. Three of them had a right-sided carcinoma and four of them a left-sided carcinoma.

\section{Histopathological staging in CME group}

Tumor histopathological classification was applied according to the World Health Organization (WHO) [22]. Staging was according to the seventh edition of the TNM classification [23]. The histopathological data of all patients are presented in Table I. Colon carcinoma of moderate differentiation (G2) was verified in 21 patients; colon carcinoma of poor differentiation (G3) in 10 patients. A curative surgical treatment (RO-resection) was performed in 27 patients whereas a non-curative surgical treatment (locally RO) was performed in 4 patients because of hepatic metastases at the time of diagnosis.

\section{Lymph node yield/CME plane quality}

The median lymph node yield was 29.6 (range 14-57). Sixteen (52\%) patients had locoregional lymph node metastases. The median lymph node ratio (LNR) in patients with lymph node metastases without distant metastases $(n=14)$ was 0.095 (range: 0.049-0.25). The median LNR in all patients with lymph node metastases (UICC stage III and IV) was 0.12 (range: 0.049-0.5). After photo documentation of all specimens and separate analysis by a pathologist a dissection along the mesocolic plane could be found in $87 \%$ of all specimens $(n=27)$. There are no differences in terms of surgical quality in the comparison between right-sided and left-sided carcinomas.

\section{Postoperative complications and outcome in CME group}

The postoperative outcome was uneventful in 23 (74\%) patients. Intraoperative blood loss was low (median: $150 \mathrm{ml}$, range: $20-300 \mathrm{ml}$ ). There was postoperative morbidity in 8 patients (Table II). Five (16\%) of them experienced surgical complications. In three patients an anastomotic leakage requiring reoperation was found. These patients had undergone emergency surgery due to bowel obstruction because of the advanced carcinoma. Surgical complications requiring conservative treatment were found in three patients. One patient who presented with an advanced free perforated sigmoid carcinoma and synchronous bilobar liver metastases died during in-hospital stay (in-hospital mortality: 3\%).

Patients were followed up until January 2018 or until death with a median follow-up of 45 (range: 36-48) months. No patient was lost to follow-up. All patients who underwent curative surgery developed no local recurrence (recurrence-free survival rate: $100 \%$ ). Four patients were diagnosed with synchronous metastatic disease in the liver. Two of the patients with synchronous hepatic metastases underwent palliative chemotherapy and died of the disease 11 and 15 months after surgery for colon cancer. The other two patients showed very good remission of the liver metastasis under systemic chemotherapy and underwent a curative hepatic metastasectomy 6 months after the surgery for colon carcinomas and are still free of disease. Three patients with stage III disease developed metachronous hepatic metastases in a median period of 18 months (range: 12-30) and are still alive, having undergone systemic chemotherapy (Table III).

\section{Non-CME group (2008-2011)}

\section{Site of carcinoma in non-CME group $(n=35)$}

The colon carcinoma was located in the caecum ( $n=9 ; 26 \%)$, ascending colon $(n=6 ; 17 \%)$, hepatic flexure $(n=3 ; 9 \%)$, transverse colon $(n=5$; $13 \%)$, splenic flexure $(n=1,3 \%)$, descending colon $(n=1 ; 3 \%)$ and sigmoid colon $(n=10 ; 29 \%)$. Twenty-seven patients underwent elective surgery and 8 patients underwent the same surgical procedure as emergency cases (Table I). 
Table II. Complications in CME $(n=31)$ and non-CME $(n=35)$ group

\begin{tabular}{|c|c|c|c|}
\hline Parameter & $\begin{array}{l}\text { CME group } \\
\begin{array}{c}(n=31) \\
n(\%)\end{array}\end{array}$ & $\begin{array}{c}\text { Non-CME group } \\
(n=35) \\
n(\%)\end{array}$ & $P$-value \\
\hline None & $23(74)$ & $18(51)$ & 0.018 \\
\hline Surgical complications*: & $5(16)$ & $10(29)$ & 0.021 \\
\hline Anastomotic leakage & $3(9)$ & $5(14)$ & 0.134 \\
\hline Sepsis & $2(6)$ & $6(17)$ & 0.034 \\
\hline Lymph fistula & $1(3)$ & $0(0)$ & $<0.001$ \\
\hline Impairment of micturition & $1(3)$ & $0(0)$ & $<0.001$ \\
\hline Hematoma & $2(6)$ & $3(9)$ & 0.473 \\
\hline Wound infection & $2(6)$ & $5(14)$ & 0.146 \\
\hline Nonsurgical complications: & $3(10)$ & $7(20)$ & 0.032 \\
\hline Cardiological & $2(6)$ & $4(12)$ & 0.065 \\
\hline Renal failure & $1(2)$ & $3(9)$ & 0.164 \\
\hline In-hospital mortality & $1(2)$ & $4(11)$ & 0.147 \\
\hline
\end{tabular}

${ }^{\star}$ More complications in 1 patient possible.

Table III. Follow-up data in CME $(n=31)$ and non-CME $(n=35)$ group

\begin{tabular}{|c|c|c|c|}
\hline Parameter & $\begin{array}{l}\text { CME group } \\
(n=31) \\
n(\%)\end{array}$ & $\begin{array}{c}\text { Non-CME group } \\
(n=35) \\
n(\%)\end{array}$ & $P$-value \\
\hline Median follow-up [months] & $45(36-48)$ & $78(58-108)$ & \\
\hline Local recurrence & $0 / 31(0)$ & $5 / 35(14.3)$ & 0.012 \\
\hline Recurrence-free survival & $31 / 31(100)$ & $30 / 35(85)$ & 0.044 \\
\hline \multicolumn{4}{|l|}{ Metastases: } \\
\hline Synchronous & 4 & 3 & \\
\hline Metachronous & 3 & 3 & \\
\hline $\begin{array}{l}\text { Metastasis-free survival (patients with } \\
\text { synchronous metastases excluded) }\end{array}$ & 24/27 (89) & $29 / 32(91)$ & 0.278 \\
\hline $\begin{array}{l}\text { Overall survival (patients with } \\
\text { synchronous metastases included) }\end{array}$ & 29/31 (94) & $24 / 35(69)$ & 0.021 \\
\hline
\end{tabular}

\section{Histopathological staging in non-CME group}

The histopathological data of all patients are presented in Table I. Colon carcinoma of moderate differentiation (G2) was verified in thirty patients; colon carcinoma of poor differentiation (G3) in five patients. A curative surgical treatment (RO-resection) was performed in 32 patients whereas a palliative, but locally RO resection, was performed in 3 patients due to synchronous metastases.

\section{Lymph node yield in non-CME group}

The median lymph node yield was 17.85 (range: $3-48)$, significantly lower than in the CME group (median: 29.6; range: 14-57; $p<0.001$ ). Fourteen
(40\%) patients had a positive lymph node status, The median LNR in patients with lymph node metastases without distant metastases $(n=11)$ was 0.18 (range: $0.05-0.55$ ). The median LNR in all patients with lymph node metastases (UICC stage III and IV) was 0.24 (range: 0.05-0.57). In both groups there was a significant difference in favor of the CME group (0.095 (range: 0.049-0.25) and 0.12 (range: $0.049-0.5$ ) respectively; $p=0.01$ and $p<0.001$ respectively).

\section{Postoperative complications and outcome in non-CME group}

Eighteen (51\%) patients had an uneventful postoperative course. The intraoperative blood 
loss was $500 \mathrm{ml}$ (range: $80-1.500 \mathrm{ml}$ ). The surgical complication rate in the non-CME group $(n=10 ; 29 \%)$ was significantly higher $(p<0.01)$ in comparison to the rate of the CME group ( $n=5,16 \%)$. Five (14\%) patients developed an anastomotic leakage requiring reoperation and the in-hospital mortality was $11 \%(n=4)$. Three of these patients died because of pneumonia and the other one because of septic shock as a result of peritonitis. Both rates were higher in comparison to the CME group ( $9 \%$ and $2 \%$, respectively), but were not statistically significant ( $p=0.13$ and $p=0.15$, respectively) (Table II).

Patients were followed up for a median period of 78 months (range: $58-108$ ). No patient was lost to follow-up. Five patients who received a curative treatment in terms of conventional colectomy developed a local recurrence (recurrence-free survival 84\%). Three patients with stage III disease developed metachronous peritoneal carcinomatosis in a median period of 13 months (range: 8-28). All patients with synchronous or metachronous metastases and the patients who developed local recurrence died during follow-up (Table III).

\section{Discussion}

Colon cancer creates huge interest, with special emphasis on optimization of therapeutic approaches [1-4]. There are significant qualitative advantages regarding the histopathological evaluation of a specimen after performing CME in comparison with conventional colon surgery $[3,4]$. The CME offers optimized oncological results through achieving maximal lymph node yield $[3,4,11-14]$. Additionally, the role of adjuvant treatment in terms of chemotherapy in patients with carcinoma UICC stage III is very important for the improvement of outcome [24, 25]. However, adjuvant chemotherapy cannot substitute for deficits in surgical quality. Therefore, the combination of CME and adjuvant chemotherapy seems to be the optimal multidisciplinary therapy. Several groups have published promising results after performing educational projects on the multidisciplinary approach of colon cancer [20] and showed that surgery for colon cancer, following the CME principles, as shown in Figures $1-4$, is a significant predictive factor for disease-free survival, especially in patients with UICC stage III disease [21]. Based on these data, our aim was to extend our educational program in Southern Europe and to evaluate the impact of CME in a high-volume center in Athens/Greece. Our results demonstrated that CME is associated with significantly better recurrence-free survival $(p<0.05)$ than conventional colon resections without increasing the postoperative complication rate. Furthermore, we showed that radical lymph node excision in terms of CME could have a significant oncologic impact since no patients with CME in curative intention had local recurrence (recurrence-free survival in CME group: $100 \%$ ). The rate of local recurrence in the group of conventional colon cancer surgery was high (14.3\%) with a recurrence-free survival of $85 \%$. Regarding this finding, our main hypothesis is that a respectable percentage of patients are indirectly being understaged from UICC stage III to UICC stage II through the non-dissected lymph nodes in the CVL area (apical lymph nodes) in the non-CME group, which can lead to development of local recurrence [26]. The risk of leaving potential regional micrometastases in the CVL area is not present if the principles of CME are followed. A further marker for surgical quality which leads to a significant improvement of oncological outcome is the intactness of the mesocolic plane [3].

Although several reports suggest that morbidity is increased through the radicalness of lymph node dissection in the context of CME, we recently reported that CME can be achieved with very low morbidity or mortality rates [2]. In the present study, patients who underwent CME had significantly lower blood loss, a lower rate of anastomotic leak $(p=0.13)$ and overall lower morbidity $(p=0.02)$ and mortality $(p=0.15)$ (Table II). A possible explanation of this finding is that surgical complications can be reduced through respecting the mesocolic plane and correctly dissecting the central vessels. Although further studies are needed to clarify potential risks of CME, we strongly believe that the main interest has to be focused on the oncological impact of the technique, which will potentially lead to significantly better survival rates in patients with UICC stage I-III colon cancer.

Most surgeons are aware of the importance of qualitative criteria regarding surgery for colon carcinoma. Apart from the importance of RO resection, producing a high quality specimen in terms of CME plays a significant role. Especially in patients with carcinoma of the transverse colon and flexures, the distant lymph nodes (extramesocolic; "third dimension": ILR, GLR) seem to be of great interest [10] and should be dissected as shown in Figure 5. These nodes have not been considered until now, although they may represent regional lymph nodes, too.

All these reasons probably contribute to the different oncological outcomes between the two collectives in the current study. Although the tumor characteristics (UICC stage in both collectives) and the rate of RO resections in both collectives are equal, the oncologic outcomes are significantly better in the CME group as far as lymph node harvesting and LNR are concerned [19]. We also detected a significant difference in terms of local recurrence. But this result could have been statis- 
tically biased through the occurrence of more patients with a T3 carcinoma in the non-CME group.

The present study has several limitations such as the relatively small number of patients treated in a single institution and the lack of a high evidence level. However, we examined all patients including emergency cases. A further bias between the groups was that there were significantly more patients with a T3 carcinoma in the non-CME group compared with the CME group. This could have had an effect on the significant difference in local recurrence in favor of the CME group. Nevertheless, numbers of patients with a nodal positive carcinoma were equal in both groups. Single-center studies have the advantage of performing the same and comparable surgical techniques.

In conclusion, complete mesocolic excision was implemented in a surgical high volume center in Athens following a preceding teaching program. One of the most important points of our study is that CME offers superior oncological results in terms of lymph node harvesting and LNR without any increase of postoperative morbidity and mortality compared to conventional surgery. Furthermore, there is a significantly better prognostic result in terms of recurrence-free survival in patients who underwent surgery according to the principles of CME. In this context, proper teaching is essential, as still many surgeons calling their personal practice "CME surgery" do not realize the true technical differences before participating in teaching programs.

\section{Acknowledgments}

Aristotelis Perrakis and Nikolaos Vassos contributed equally to the manuscript.

\section{Conflict of interest}

The authors declare no conflict of interest.

\section{References}

1. Hohenberger W, Weber K, Matzel K, Papadopoulos T, Merkel S. Standardized surgery for colonic cancer: complete mesocolic excision and central ligation - technical notes and outcome. Colorectal Dis 2009; 11: 354-64.

2. Weber K, Merkel S, Perrakis A, Hohenberger W. Is there a disadvantage to radical lymph node dissection in colon cancer? Int J Colorectal Dis 2013; 28: 217-26.

3. West NP, Hohenberger W, Weber K, Perrakis A, Finan PJ, Quirke P. Complete mesocolic excision with central vascular ligation produces an oncologically superior specimen compared with standard surgery for carcinoma of the colon. J Clin Oncol 2010; 28: 272-8.

4. West NP, Kobayashi H, Takahashi K, et al. Understanding optimal colonic cancer surgery: comparison of Japanese D3 resection and European complete mesocolic excision with central vascular ligation. J Clin Oncol 2012; 30: 1763-9.
5. Heald RJ, Husband EM, Ryall RDH. The mesorectum in rectal cancer surgery - the clue to pelvic recurrence? Br J Surg 1982; 69: 613-6.

6. Heald RJ, Ryall RD. Recurrence and survival after total mesorectal excision for rectal cancer. Lancet 1986; 327 : 1479-82.

7. Cecil TD, Sexton R, Moran BJ, Heald RJ. Total mesorectal excision results in low local recurrence rates in lymph node positive rectal cancer. Dis Colon Rectum 2004; 47: 1145-50.

8. Nagtegaal ID, van de Velde CJ, van der Worp E, Kapiteijn E, Quirke P, van Krieken JH; Cooperative Clinical Investigators of the Dutch Colorectal Cancer Group. Macroscopic evaluation of rectal cancer resection specimen: clinical significance of the pathologist in quality control. J Clin Oncol 2002; 20: 1729-34.

9. Quirke P, Steele R, Monson J, et al.; MRC CRO7/NCIC-CTG CO16 Trial Investigators; NCRI Colorectal Cancer Study Group. Effect of the plane of surgery achieved on local recurrence in patients with operable rectal cancer: a prospective study using data from the MRC CR07 and NCIC-CTG CO16 randomised clinical trial. Lancet 2009; 373: 821-8.

10. Perrakis A, Weber K, Merkel S, et al. Lymph node metastasis of carcinomas of transverse colon including flexures. Consideration of the extramesocolic lymph node stations. Int J Colorectal Dis 2014; 29: 1223-9.

11. Chen SL, Bilchik AJ. More extensive nodal dissection improves survival for stages I to III of colon cancer: a population-based study. Ann Surg 2006; 244: 602-10.

12. Johnson PM, Porter GA, Ricciardi R, Baxter NN. Increasing negative lymph node count is independently associated with improved long-term survival in stage IIIB and IIIC colon cancer. J Clin Oncol 2006; 24: 3570-5.

13. Schumacher P, Dineen S, Barnett C Jr, Fleming J, Anthony $\mathrm{T}$. The metastatic lymph node ratio predicts survival in colon cancer. Am J Surg 2007; 194: 827-32.

14. Le Voyer TE, Sigurdson ER, Hanlon AL, et al. Colon cancer survival is associated with increasing number of lymph nodes analyzed: a secondary survey of intergroup trial INT-0089. J Clin Oncol 2003; 21: 2912-9.

15. Bokey L, Chapuis PH, Chan C, et al. Long-term results following an anatomically-based surgical technique for resection of colon cancer: a comparison with results from complete mesocolic excision. Colorectal Dis 2016; 18: 676-83.

16. Toyota S, Ohta H, Anazawa S. Rationale for extent of lymph node dissection for right colon cancer. Dis Colon Rectum 1995; 38: 705-11.

17. Killeen S, Mannion M, Devaney A, Winter DC. Complete mesocolic resection and extended lympadenectomy for colon cancer: a systematic review. Colorectal Dis 2014; 16: 577-94.

18. Kontovounisios C, Kinross J, Tan E, Brown G, Rasheed S, Tekkis P. Complete mesocolic excision in colorectal cancer: a systematic review. Colorectal Dis 2015; 17: 7-16.

19. Gouvas N, Agalianos C, Papaparaskeva K, Perrakis A, Hohenberger W, Xynos E. Surgery along the embryological planes for colon cancer: a systematic review of complete mesocolic excision. Int J Colorectal Dis 2016; 31: 1577-94.

20. Bernhoff R, Martling A, Sjövall A, Granath F, Hohenberger W, Holm T. Improved survival after an educational project on colon cancer management in the county of Stockholm - a population based cohort study. Eur J Surg Oncol 2015; 41: 1479-84.

21. Bertelsen CA, Neuenschwander AU, Jansen JE, et al. Disease-free survival after complete mesocolic exci- 
sion compared with conventional colon cancer surgery: a retrospective, population-based study. Lancet Oncol 2015; 16: 161-8.

22. Jass JR, Sobin LH. Histological classification of tumours. $2^{\text {nd }}$ ed. WHO International Histological Classification of Tumours. Springer, Berlin 1989.

23. Sobin LH, Gospodarowicz M, Wittekind C. UICC TNM Classification of Malignant Tumors. $7^{\text {th }}$ ed. John Wiley \& Sons, New York 2009.

24. André T, Boni C, Mounedji-Boudiaf L, et al. Multicenter International Study of Oxaliplatin/5-Fluorouracil/Leucovorin in the Adjuvant Treatment of Colon Cancer (MOSAIC) Investigators Oxaliplatin, fluorouracil, and leucovorin as adjuvant treatment for colon cancer. N Eng J Med 2004; 350: 2343-51.

25. Link KH, Kornmann M, Staib L, Redenbacher M, Kron M, Beger HG; Study Group Oncology of Gastrointestinal Tumors. Increase of survival benefit in advanced resectable colon cancer by extent of adjuvant treatment: results of a randomized trial comparing modulation of 5 -FU + levamisole with folinic acid or with interferonalpha. Ann Surg 2005; 242: 178-87.

26. Liang JT, Huang KC, Lai HS, Lee PH, Sun CT. Oncologic results of laparoscopic D3 lymphadenectomy for male sigmoid and upper rectal cancer with clinically positive lymph nodes. Ann Surg Oncol 2007; 14: 1980-90. 